\title{
Nanotheranostics
}

2018; 2(3): 211-221. doi: 10.7150/ntno.25119

Research Paper

\section{Tumor Theranostics of Transition Metal lons Loaded Polyaminopyrrole Nanoparticles}

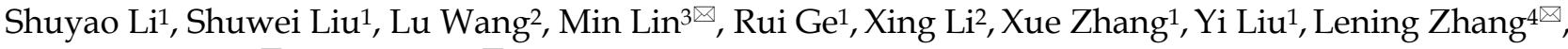 \\ Hongchen Sun ${ }^{1,2}$, Hao Zhang ${ }^{1 凶}$ and Bai Yang ${ }^{1}$ \\ 1. State Key Supramolecular Structure and Materials Laboratory, College of Chemistry, Jilin University, Changchun 130012, P. R. China; \\ 2. The Oral Pathology Department, School and Hospital attached to Stomatology, Jilin University, Changchun 130021, P. R. China; \\ 3. Collaborative Innovation Center attached to Marine Biomass Fibers, Shandong Province Materials and Textiles, Marine Biobased Materials Institute, \\ Materials Science and Engineering School, Qingdao University, Qingdao 266071, P. R. China; \\ 4. Department of Thoracic Surgery, China-Japan Union Hospital, Jilin University, Changchun 130033, P. R. China.
}

$\square$ Corresponding authors: Hao Zhang, PhD, State Key Supramolecular Structure and Materials Laboratory, College of Chemistry, Jilin University, Changchun 130012, P. R. China. Tel: +86 431 85159205; Email: hao_zhang@jlu.edu.cn. Hongchen Sun, PhD, The Oral Pathology Department, School and Hospital attached to Stomatology, Jilin University, Changchun 130021, P. R. China. Tel: +86 431 88796010; Email: hcsun@jlu.edu.cn. Min Lin, PhD, Collaborative Innovation Center attached to Marine Biomass Fibers, Shandong Province Materials and Textiles, Marine Biobased Materials Institute, Materials Science and Engineering School, Qingdao University, Qingdao 266071, P. R. China. Tel: +86 431 85159205; Email: linmin900401@126.com. Lening Zhang, PhD, Department of Thoracic Surgery, China-Japan Union Hospital, Jilin University, Changchun 130033, P. R. China. Tel: +86 431 85159205; Email: 951446482@qq.com.

(C) Ivyspring International Publisher. This is an open access article distributed under the terms of the Creative Commons Attribution (CC BY-NC) license (https://creativecommons.org/licenses/by-nc/4.0/). See http://ivyspring.com/terms for full terms and conditions.

Received: 2018.01.26; Accepted: 2018.04.22; Published: 2018.05.15

\begin{abstract}
Polypyrrole (PPy) nanoparticles (NPs) possess high near-infrared absorption and good biosafety, showing the potentials as photothermal therapeutic materials. However, the single function and the weak diagnostic function limit the further combination with other functional units to achieve theranostics. In this work, polyaminopyrrole $\left(\mathrm{PPy}-\mathrm{NH}_{2}\right)$ is demonstrated as the alternative of PPy for preparing NPs. Because of the amino group, metal ions, such as $\mathrm{Cu}$ (II) and $\mathrm{Fe}$ (III) can be loaded in PPy- $\mathrm{NH}_{2} \mathrm{NPs}$, which extends the applications in multimodal theranostics. Systematical studies reveal that the contribution of $\mathrm{Cu}$ (II) in multimodal theranostics is greater than $\mathrm{Fe}(\mathrm{III})$. $\mathrm{Cu}$ can enhance $T_{1}$ response signal for magnetic resonance imaging (MRI) and be released controllably in the organism, leading to the effect of chemotherapy. Therefore, $\mathrm{Cu}(\mathrm{II})$ and $\mathrm{Fe}(\mathrm{III})$ co-loaded PPy- $\mathrm{NH}_{2}$ NPs are defined as CuPPy- $\mathrm{NH}_{2}$ NPs. Experimental results indicate that the optimal size of CuPPy- $\mathrm{NH}_{2} \quad \mathrm{NPs}$ is $50.2 \mathrm{~nm}$. The photothermal transduction efficiency is $76.4 \%$. After thermochemotherapy, a complete ablation of human oral epithelial carcinoma tumors is observed. No tumor recurrence is found.

Methods: $\mathrm{Cu}(\mathrm{II})$ and $\mathrm{Fe}(\mathrm{III})$ co-loaded $\mathrm{PPy}-\mathrm{NH}_{2}$ NPs are prepared through oxidation polymerization by mixing $\mathrm{Py}-\mathrm{NH}_{2}, \mathrm{CuCl}_{2}$, and $\mathrm{FeCl}_{3}$ in water under stirring at room temperature, which are defined as CuPPy- $\mathrm{NH}_{2} \mathrm{NPs}$. The as-prepared CuPPy- $\mathrm{NH}_{2} \mathrm{NPs}$ are tested with a variety of cell and animal experiments for tumor theranostics.

Results: CuPPy- $\mathrm{NH}_{2}$ NPs have good light stability, photothermal stability, biosafety and low toxicity. The optimal size of theranostic CuPPy- $\mathrm{NH}_{2} \mathrm{NPs}$ is $50.2 \mathrm{~nm}$, which present a photothermal transduction efficiency of $76.4 \%$. The doped $\mathrm{Cu}$ (II) ions also show chemotherapeutic behavior. After thermochemotherapy, a complete ablation of human oral epithelial carcinoma tumors is observed. No tumor recurrence is found. Because of the unpaired electron in $\mathrm{Cu}$ atomic orbits, $\mathrm{CuPPy}-\mathrm{NH}_{2}$ NPs also show $\mathrm{T}_{1}$-weighted magnetic resonance imaging.

Conclusions: This kind of transition metal-doped polymer gives a competitive approach for designing and fabricating multimodal theranostic nanodevices, which shows the potential in tumor treatment.
\end{abstract}

Key words: polyaminopyrrole nanoparticles, theranostics, magnetic resonance imaging, thermochemotherapy 


\section{Introduction}

Tumor theranostics is a vitally significant application for nano-medical science [1-7]. Plenty of nanoplatforms, constructing from noble metal nanoparticles (NPs) [8-11], carbon-based materials [12-14], organic compounds [15, 16], polymers [17, 18] and some other inorganic NPs such as $\mathrm{Fe}_{3} \mathrm{O}_{4}[19,20]$, $\mathrm{SiO}_{2}$ [21-24], copper chalcogenides [25-27], are tested as novel agents for tumor diagnosis and combination therapies. Apart from these existing building blocks, transitional metal ions also exhibit theranostic functions [28-31]. For example, unpaired electrons in atomic orbits endow $\mathrm{Mn}(\mathrm{II}), \mathrm{Co}(\mathrm{II}), \mathrm{Cu}(\mathrm{II}), \mathrm{Fe}(\mathrm{III})$, and etc. as contrast agents for magnetic resonance imaging (MRI) [32-34], which is a precise and free of radiation imaging technique for the diagnosis of soft tissue lesion [35-38]. Some of the transitional metal ions also carry certain dosage of toxicity, which can be used as chemotherapeutic drugs for tumor treatment $[39,40]$. Meanwhile, many transitional metal elements are essential to maintaining body health. Fe is crucial for the hemoglobins [41], $\mathrm{Cu}$ is important for blood stream formation [42], $\mathrm{Zn}$ influences hormonal level [43], and Co can be used for nerve repairing [44]. However, they are rarely exploited in tumor theranostics. The main hindrance is that metal ions cannot be directed injected in the form of salt or organic molecules chelated compounds. Metal cations can easily disturb the physiological equilibrium, change the activities of proteins and even induce severe toxicity, raising concerns for biosafety $[45,46]$.

Proper engineering arrangement is required for metal ions before medical applications. Biosafety polymer enveloping is a facile strategy and it has been used for the surface passion of NPs, increasing structural stability as well as surface passivation and reducing toxicity from releasing [47]. One of the frequently used polymers is polypyrrole (PPy) due to the easy fabrication. PPy is a conductive polymer with good biosafety and it is widely used as covering material of Au-based nanomaterials, $\mathrm{SiO}_{2} \mathrm{NPs}$ and some supramolecular structures [8, 22]. Additionally, Liu et al. reported pure PPy NPs as sufficient heat generator under NIR laser irradiation for the effective photothermal ablation of malignant tumors [48]. However, PPy NPs still show limitation in several aspects. First, the function of tumor diagnosis should be included. Second, appropriate method is required to track and identify PPy NPs in vivo. Thirdly, though Zhen and his colleges revealed the biodistribution of $\mathrm{SiO}_{2} @ P P y$ [49], the accumulation of pure PPy NPs in vital organs and tumor needs detailed study for the full estimation after systemic injection. Hence, properly engineered metal ions in PPy NPs would solve aforementioned aspects perfectly. On the one hand, by importing imaging capability from metal ions, PPy NPs can achieve tumor diagnosis and therapy simultaneously [50]. On the other hand, metal elements labeling PPy can provide the feasibility to monitor the change of PPy concentration in vivo through MRI, such as in blood, brain, muscles, and inner visceral organs [51-53].

The tumor theranostic performance is also affected by the doping quantity of metal ions, while the monomer pyrrole (Py) is of low coordination capability to metal ions, resulting into low loading capability of PPy NPs. Moreover, when chemotherapeutic metal ions is loaded, the weak coordination interaction between metal ions and PPy carriers may break up in normal physical conditions, causing damages to normal tissue [54, 55]. Hence, stronger coordination bonding is required to improve the metal ion loading efficiency and the biosafety. In this work, we replace Py with $\mathrm{Py}-\mathrm{NH}_{2}$ to increase the coordinative ability with transitional metal elements. Thus, $\mathrm{Cu}(\mathrm{II})$ and $\mathrm{Fe}(\mathrm{III})$ are loaded in $\mathrm{PPy}_{-} \mathrm{NH}_{2}$ $\left(\mathrm{CuPPy}-\mathrm{NH}_{2}\right)$ NPs during the polymerization. Both $\mathrm{Cu}(\mathrm{II})$ and $\mathrm{Fe}(\mathrm{III})$ can equip $\mathrm{PPy}-\mathrm{NH}_{2} \mathrm{NPs}$ with MRI tumor diagnosis $[39,56]$. Besides, $\mathrm{Cu}$ (II) can also label PPy- $\mathrm{NH}_{2}$ NPs and make the NPs traceable in blood and vital organs $[57,58]$. After $\mathrm{CuPPy}-\mathrm{NH}_{2} \mathrm{NPs}$ reach cancerous area based on the enhance permeability and retention (EPR) effect, $\mathrm{Cu}$ (II) can be released from NPs and exhibit chemotherapeutic behavior [9]. The onefold tumor inhibition rate for chemotherapy is 70.6 $\%$. Further combining photothermal therapy, the thermochemotherapy can completely ablate tumors without recurrence. The biosafety of $\mathrm{CuPPy}-\mathrm{NH}_{2} \mathrm{NPs}$ is also carefully explored and the results indicate that $\mathrm{CuPPy}-\mathrm{NH}_{2} \mathrm{NPs}$ are safe and of high performance in tumor theranostics.

\section{Methods}

\section{Materials}

All the reagents were commercially available products and used directly without further purification. Deionized water was used directly in all experiments. Propidium iodide (PI) and fluorescein diacetate (FDA) were purchased from Invitrogen. 1-Aminopyrrole $\left(\mathrm{Py}-\mathrm{NH}_{2},>98.0 \%\right)$ was purchased from Tokyo Chemical Industry. Ferric trichloridehexahydrate $\left(\mathrm{FeCl}_{3} \cdot 6 \mathrm{H}_{2} \mathrm{O}\right)$, copper chloride dehydrate $\left(\mathrm{CuCl}_{2} \cdot 2 \mathrm{H}_{2} \mathrm{O}\right)$, 3-(4,5-dimethyl-2-thiazolyl)-2,5-diphenyl-2-H-tetrazoliumbromide (MTT), mercaptoethylamine (MA, 99+\%), mercaptoglycerol, 3-mercaptopropionic acid (MPA, 99+\%) and glutathione (GSH, 99\%) were got in Sigma-Aldrich. Ammonium hydroxide $\left(\mathrm{NH}_{3} \cdot \mathrm{H}_{2} \mathrm{O}, 25 \%\right)$ was purchased from Beijing Chemical Works. 


\section{Preparation of CuPPy-NH2, PPy- $\mathrm{NH}_{2}$ and Cu-loaded polypyrrole NPs}

$\mathrm{CuPPy}-\mathrm{NH}_{2}$ NPs were prepared by mixing 0.5 mmol Py- $\mathrm{NH}_{2}, 1 \mathrm{mmol} \mathrm{CuCl}$, and $4 \mathrm{mmol} \mathrm{FeCl}_{3}$ in $120 \mathrm{~mL}$ water under stirring at room temperature for $24 \mathrm{~h}$. By reducing the dosage of Fe(III) from 4.0 to 3.5, 3 and $2.5 \mathrm{mmol}$, the diameter of $\mathrm{CuPPy}-\mathrm{NH}_{2} \mathrm{NPs}$ are adjustable from $50.2 \pm 5.0$ to $20.3 \pm 3.0 \mathrm{~nm}$. Through the similar method, $\mathrm{PPy}-\mathrm{NH}_{2}$ and $\mathrm{Cu}$-loaded polypyrrole (CuPPy) NPs were also prepared. The products were collected after high speed centrifugation for $20 \mathrm{~min}$ under $2000 \mathrm{rcf}\left(\mathrm{g}^{\prime} \mathrm{s}\right)$. The NPs were dispersed in deionized water for further tests and characterizations.

\section{Metal ion release}

$5 \mathrm{mg} / \mathrm{mL} \mathrm{CuPPy}-\mathrm{NH}_{2}$ NPs aqueous solution were mixed with $10 \mathrm{mM}$ ammonia $\left(-\mathrm{NH}_{2}\right)$, sodium citrate $(-\mathrm{COOH})$ and mercaptoglycerol $(-\mathrm{SH})$, respectively. At different time intervals, through high speed centrifugation the $\mathrm{CuPPy}-\mathrm{NH}_{2} \quad \mathrm{NPs}$ were discarded. The released dose of ions in supernatant was determined by inductive coupled plasma atomic emission spectrometer (ICP-AES).

\section{Cytotoxicity test and the photothermal effect in vitro}

The human oral epithelial carcinoma (KB) cells were incubated with different concentrations of $\mathrm{CuPPy}-\mathrm{NH}_{2} \mathrm{NPs}$. After $24 \mathrm{~h}$ in standard cell media, the cell viability for $\mathrm{KB}$ cells was determined by a standard MTT assay on 96-well plates. The MTT test was measured by the optical density (OD) at $490 \mathrm{~nm}$. As for the in vitro of photothermal therapy, KB cells were incubated with the concentration of $50 \mu \mathrm{g} / \mathrm{mL}$ $\mathrm{CuPPy}-\mathrm{NH}_{2} \mathrm{NPs}$ for $30 \mathrm{~min}$. Then each sample was irradiated at different power densities by an $808 \mathrm{~nm}$ NIR laser for $8 \mathrm{~min}$. As for the control group, cell viability was tested at the same conditions without adding $\mathrm{CuPPy}-\mathrm{NH}_{2}$ NPs. Each experiment was repeated for five times.

\section{PI and FDA co-staining assay}

The treatment efficacy was revealed by PI and FDA. $30000 \mathrm{~KB}$ cells were seeded in a 12-well plate. The KB cells were incubated for $30 \mathrm{~min}$ with the concentration of $50 \mu \mathrm{g} / \mathrm{mL} \quad \mathrm{CuPPy}-\mathrm{NH}_{2} \quad \mathrm{NPs}$ containing $100 \mu \mathrm{g} / \mathrm{mL}$ of GSH in cell culture and incubated with cells. Each plate was irradiated at 0.33 $\mathrm{W} / \mathrm{cm}^{2}$ for $0,3,8$, and $10 \mathrm{~min}$, respectively, by an 808 $\mathrm{nm}$ laser. After that, $1 \mu \mathrm{g} / \mathrm{mL}$ PI and FDA were added into the $\mathrm{KB}$ cell culture in sequence with incubation for $15 \mathrm{~min}$ and $30 \mathrm{~s}$, respectively. Finally, fluorescent photographs were taken under the excitation of 488 and $543 \mathrm{~nm}$, respectively.

\section{Animal experiments}

4-6 weeks' old balb/c. nude (weighing 18g) were purchased from Beijing Huafukang Biological Technology Co. Ltd. The mice were used under protocols approved by Jilin University Laboratory Animal Center. After one week's observation, their weights got a basic normal value around 19 g. $1.5 \times$ $10^{6}$ of KB cells dispersed in $100 \mu \mathrm{L}$ of cell culture were injected subcutaneously into the right back leg of the mice. The tumor size was measured by a digital caliper every day. When the average tumor size reached $\sim 100 \mathrm{~mm}^{3}$, the mice were allocated into four groups: control group, laser only group, chemotherapy (CuPPy-NH $\mathrm{N}_{2} \mathrm{NPs}$ only) group, and thermo-chemotherapy (laser $+\mathrm{CuPPy}-\mathrm{NH}_{2} \mathrm{NPs}$ ) group. Moreover, the mice were administrated with $\mathrm{CuPPy}-\mathrm{NH}_{2} \mathrm{NPs}$ by intravenous (i.v.) injection. The chemotherapy group and thermo-chemotherapy group were injected with $50 \mu \mathrm{L} 1 \mathrm{mg} / \mathrm{mL} \mathrm{CuPPy}-\mathrm{NH}_{2}$ NPs. And as for the control group and laser only group were intravenously injected with same volume of saline. The tumors in laser only and thermochemotherapy group were irradiated for $20 \mathrm{~min}$ by an $808 \mathrm{~nm}$ laser at $0.33 \mathrm{~W} / \mathrm{cm}^{2}$ two days after injection. In addition, the sizes of the tumor and the weights of the mouse were measured every other day. The tumor volume was calculated by the following formula:

$$
\mathrm{V}=1 / 2 \cdot \mathrm{L} \cdot \mathrm{D}^{2}
$$

$(\mathrm{L}(\mathrm{mm})=$ the tumor sizes in long axes; $\mathrm{D}(\mathrm{mm})=$ the tumor sizes in short axes). After CuPPy- $\mathrm{NH}_{2} \mathrm{NPs}$ injection for 16 days, the tumors of the treatment groups and the control group above were taken for further experiments: surgery, weighted by a scale and taken photos through a camera. The tumors and major organs and tissues (lungs, liver, heart, spleen, and kidneys) from each group were taken after heart perfusion and they were also soaked with formalin for further hematoxylin-eosin (H\&E) staining.

\section{Blood circulation and biodistribution}

For blood circulation of $\mathrm{CuPPy}-\mathrm{NH}_{2} \mathrm{NPs}$, the same dose of blood $(8 \mu \mathrm{L})$ was collected from each mouse at different time intervals and then dissolved in chloroazotic acid $\left(\mathrm{HCl} / \mathrm{HNO}_{3}=3: 1\right)$. And the mixed solution was analyzed by ICP-AES to determine the total amount of $\mathrm{Cu}$ in the blood. Major organs and tissues (liver, spleen, kidneys and tumor) from balb/c. nude $(n=8)$ were collected at the indicated time point to demonstrate the $\mathrm{CuPPy}-\mathrm{NH}_{2}$ NPs biodistribution.

\section{MRI study in vivo}

The mice were planted with one tumor in the right side of the back legs. Each mouse was 
intravenously injected with $50 \mu \mathrm{L} 1 \mathrm{mg} / \mathrm{mL}$ of CuPPy- $\mathrm{NH}_{2}$ NPs. $24 \mathrm{~h}$ later, the mice were anaesthetized and imaged under $1.5 \mathrm{~T}$ magnetic field.

\section{Characterization}

The UV-visible (UV-vis) absorption spectrum was recorded using a UV-3600 UV-vis spectrophotometer. Transmission electron microscopy (TEM) was characterized by a Hitachi H-800 electron microscope. The Dynamic light scattering (DLS) measurements were implemented using Zetasizer NanoZS (Malvern Instruments). The tests above were all conducted at room temperature. The infrared thermal images photos were taken by FLUKE infrared Ray (IR) thermal camera. The concentration of $\mathrm{Cu}$ was measured by ICP-AES. VG ESCALAB MKII spectrometer with an $\mathrm{Mg} \mathrm{Ka}$ excitation $(1253.6 \mathrm{eV})$ was used to perform X-ray photoelectron spectroscopy (XPS) investigation.

\section{Results and Discussion}

In our experiment, $\mathrm{Cu}(\mathrm{II})$ and $\mathrm{Fe}(\mathrm{III})$ chelated PPy-NH $\mathrm{NH}_{2}\left(\mathrm{CuPPy}-\mathrm{NH}_{2}\right)$ NPs are prepared through oxidative polymerization. By changing the initiating concentration of $\mathrm{Fe}(\mathrm{III})$, the obtained NPs are quasi-spherical with the adjustable diameters from $50.2 \pm 5.0$ to $20.3 \pm 3.0 \mathrm{~nm}$ (Figure 1A-D). High concentration of $\mathrm{Fe}(\mathrm{III})$ is used to initial the oxidative polymerization of $\mathrm{Py}-\mathrm{NH}_{2}$, where the molar ratio of $\mathrm{Fe}(\mathrm{III})$ to $\mathrm{Py}-\mathrm{NH}_{2}$ is 5 8:1. The excessive Fe(III) in the reaction plays three roles, namely, improving the loading quantity of $\mathrm{Fe}(\mathrm{III})$ in $\mathrm{PPy}-\mathrm{NH}_{2} \mathrm{NPs}$, ensuring the complete polymerization of $\mathrm{Py}-\mathrm{NH}_{2}$ and providing good colloidal stability. In aqueous
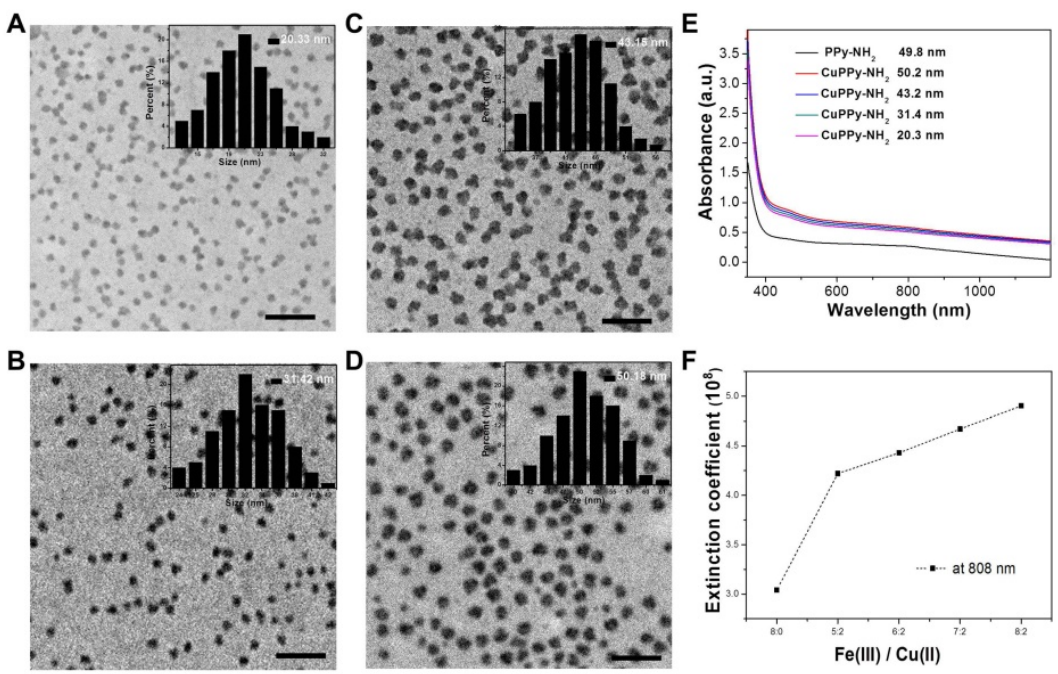

Figure 1. TEM images of the as-prepared CuPPy- $\mathrm{NH}_{2} \mathrm{NPs}$ with the diameter of $20.3 \pm 3.0$ (A), 31.4 \pm 8.0 (B), $43.2 \pm 4.0$ (C), and $50.2 \pm 2.0 \mathrm{~nm}(\mathrm{D})$. The scale bar in (A)-(D) represents $200 \mathrm{~nm}$. (E) UV-vis absorption spectra of the as-prepared PPy- $\mathrm{NH}_{2}$ and $\mathrm{CuPPy}-\mathrm{NH}_{2} \mathrm{NPs}$ with different diameter. $(\mathrm{F})$ The light extinction coefficients of CuPPy-NH $\mathrm{NH}_{2} \mathrm{NPs}$ at $808 \mathrm{~nm}$. solution, PPy NPs are conventional prepared in polymer stabilizers like poly (vinyl alcohol) considering the easy aggregation for pure PPy NPs [48]. But in our system, Fe(III) gives the essential surface potentials for PPy- $\mathrm{NH}_{2}$ NPs $(+19 \mathrm{mV})$ by ionization, which provides the critical electrostatic repulsions among NPs without protonating amino groups. Further increasing the feeding ratio of $\mathrm{Fe}(\mathrm{III})$ to $\mathrm{Py}-\mathrm{NH}_{2}$ above 9:1, the sizes of NPs would not grow larger than $50 \mathrm{~nm}$ because of the fast consumption of monomer (Figure S1). $\mathrm{Cu}$ (II) is also loaded during the polymerization under competitive coordination with $\mathrm{Fe}(\mathrm{III})$. The loading $\mathrm{Cu}(\mathrm{II})$ could hardly change the quasi-spherical morphology and the size of $\mathrm{PPy}-\mathrm{NH}_{2}$ NPs (Figure S2A). However, the light absorption is enhanced in large scale from visible to near-infrared (NIR) region after the loading of $\mathrm{Cu}$ (II) (Figure 1E). As for the NPs of $50.2,49.8 \mathrm{~nm}$, light extinction coefficient at $808 \mathrm{~nm}$ is $4.90 \times 10^{8}$ and $3.04 \times 10^{8} \mathrm{M}^{-1} \mathrm{~cm}^{-1}$ with and without chelating $\mathrm{Cu}$ (II) (Figure $1 \mathrm{~F}$ ). The enhancement of light absorption results from the vis-NIR light extinction ability of cupreous complexes [10, 39]. When amino groups coordinate $\mathrm{Cu}(\mathrm{II})$, the complexes exhibit enhanced absorption peak from 0.6 to 0.8 (Figure S3). In addition, the size of NPs also affects the light extinction capability (Figure 1E, F, S4). The light extinction coefficients are $4.22 \times 10^{8}, 4.43 \times 10^{8}, 4.67 \times 10^{8}$ and $4.90 \times 10^{8} \mathrm{M}^{-1} \mathrm{~s}^{-1}$ for the CuPPy-NH${ }_{2} \mathrm{NPs}$ of 20.3 , $31.4,43.2$ and $50.2 \mathrm{~nm}$, respectively.

The structural information of $\mathrm{CuPPy}-\mathrm{NH}_{2} \mathrm{NPs}$ is further revealed by XPS. The Fe: $\mathrm{Cu}$ ratio of $4: 1$ is chosen to make the CuPPy-NH2 NPs. As shown in Figure 2, the binding energy of $\mathrm{N}$ shows the linkage of $\mathrm{N}-\mathrm{H}, \mathrm{N}-\mathrm{Cu}$ and $\mathrm{N}-\mathrm{Fe}$ at 399.7, 400.7 and $401.2 \mathrm{eV}$, respectively [59]. In addition, the binding energy of $\mathrm{Cu}$ also reveals the linkage of $\mathrm{Cu}-\mathrm{O}$ and $\mathrm{Cu}-\mathrm{Cl}$ (Figure $2 \mathrm{~B}$ ) [60], which results from the hydration water and counterions of $\mathrm{Cl}$ (Figure 2C) [61]. By comparison, the $\mathrm{N}$ spectrum of PPy- $\mathrm{NH}_{2}$ NPs without chelating $\mathrm{Cu}(\mathrm{II})$ only shows the linkage of $\mathrm{N}-\mathrm{H}$ and $\mathrm{N}-\mathrm{Fe}$ at 399.6, $401.0 \mathrm{eV}$ (Figure S5A) [59]. Moreover, $\mathrm{Cu}$ is not covalently bound to PPy NPs. But a slight $\mathrm{Cu}$ can still adsorb on PPy NPs, despite the content of $\mathrm{Cu}$ is only $0.7 \%$. Due to the low coordinating capability of $\mathrm{Py}$, we could hardly observe the linkage of $\mathrm{N}$-metal from the CuPPy NPs, and the content of $\mathrm{Cu}$ (II) cannot be improved in CuPPy NPs (Figure S5A and B). Further combining the ICP-AES data, the formula of CuPPy-NH$H_{2}$ NPs and $\mathrm{PPy}-\mathrm{NH}_{2}$ NPs are speculated as 
$\left[\mathrm{C}_{4} \mathrm{~N}_{2} \mathrm{H}_{4}\left(\mathrm{CuCl}_{2}\right)_{0.6} \cdot\left(\mathrm{H}_{2} \mathrm{O}\right)_{0.2}\left(\mathrm{FeCl}_{3}\right)_{0.17}\right]_{\mathrm{n}}$ and $\left[\mathrm{C}_{4} \mathrm{~N}_{2} \mathrm{H}_{4}(\mathrm{Fe}\right.$ $\left.\left.\mathrm{Cl}_{3}\right)_{0.22}\right]_{\mathrm{n}}$, respectively.

The loading of $\mathrm{Cu}(\mathrm{II})$ improves the photothermal performance of $\mathrm{PPy}_{-} \mathrm{NH}_{2} \mathrm{NPs}$. As shown in Figure 3, the temperature of aqueous solution containing NPs exhibits dramatic increments while irradiated by an $808 \mathrm{~nm}$ laser. When the laser power density is set at $3.5 \mathrm{~W} / \mathrm{cm}^{2}$, the increment in temperature is $47.4^{\circ} \mathrm{C}$ for CuPPy- $\mathrm{NH}_{2} \mathrm{NPs}$ after 20 min irradiation, while it is only $26.2{ }^{\circ} \mathrm{C}$ for $\mathrm{PPy}^{-\mathrm{NH}_{2}}$ without loading $\mathrm{Cu}(\mathrm{II})$ (Figure 3A). The temperature increment is also affected by the size of $\mathrm{CuPPy}-\mathrm{NH}_{2} \mathrm{NPs}$, since larger NPs possess higher light extinction capability (Figure 1E) [8]. As shown in Figure 3B, the NPs of $50 \mathrm{~nm}$ exhibit the best photothermal performance. Within 20 min irradiation, the temperature increment for $50 \mathrm{~nm}$ is $3{ }^{\circ} \mathrm{C}$ higher than that of $20 \mathrm{~nm}$ (Figure 3B). Besides, the photothermal converting performance is also influenced by the laser power densities and NPs concentrations (Figure 3C and D). When larger sum of NIR light or higher concentration of NPs is applied, the temperature increment is also higher because of collective heating effect [48]. We additionally determined the photothermal transduction efficiency

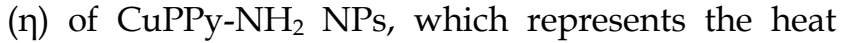
converting efficiency from absorbed light. By recording the real-time temperature of aqueous solution containing $\mathrm{CuPPy}-\mathrm{NH}_{2}$ NPs during the heating and cooling procedure, the $\eta$ of $\mathrm{CuPPy}-\mathrm{NH}_{2}$ NPs is calculated as $76.4 \%$, while it is only $54.0 \%$ for $\mathrm{PPy}-\mathrm{NH}_{2} \mathrm{NPs}$ without loading $\mathrm{Cu}$ (II) (Figure S6). These evidences confirm that $\mathrm{Cu}(\mathrm{II})$ is the main contributor to the enhancement of photothermal performance. It should be noted that considering the DLS diameter of $50 \mathrm{~nm}$ NPs is $98.0 \mathrm{~nm}$ (Figure S7). The real size of NPs may be between TEM observation and DLS measurement in biological experiments because of the complex physiological environment. As reported, the NPs with diameters of $10-100 \mathrm{~nm}$ are most suitable for tumor theranostics applications. The $\mathrm{CuPPy}-\mathrm{NH}_{2}$ NPs of $50.2 \mathrm{~nm}$ is exploited in the following theranostic performance tests.

Since $\mathrm{Fe}(\mathrm{III})$ and $\mathrm{Cu}(\mathrm{II})$ possess unpaired electrons in the atomic orbits, they can shorten the longitudinal relaxation $\left(\mathrm{T}_{1}\right)$ of surrounding protons in high-energy of magnetic fields [25, 39]. As revealed in concentration dependent $\mathrm{T}_{1}$-weighted MRI images (Figure 4B), both $\mathrm{Cu}(\mathrm{II})$ and $\mathrm{Fe}(\mathrm{III})$ could lighten up water under $1.5 \mathrm{~T}$ magnetic field. And the respective relaxation rate $\left(\mathrm{r}_{1}\right)$ of $\mathrm{Cu}(\mathrm{II})$ and $\mathrm{Fe}(\mathrm{III})$ is 0.21 and 0.70 $\mathrm{mM}^{-1} \mathrm{~s}^{-1}$ as determined by a $500 \mathrm{M}$ nuclear magnetic resonance (NMR) spectrometer (Figure 4A). The loading $\mathrm{Fe}(\mathrm{III})$ and $\mathrm{Cu}(\mathrm{II})$ would endow the $\mathrm{CuPPy}-\mathrm{NH}_{2}$ NPs with enhanced contrasting performance in MRI. CuPPy- $\mathrm{NH}_{2}$ NPs exhibit continuous enhancement of MRI signals with increasing concentrations (Figure 4B). The $r_{1}$ is tested as $4.72 \mathrm{mM}^{-1} \mathrm{~s}^{-1}$ based on the concentration of $\mathrm{Cu}(\mathrm{II})$ (Figure 4A), which is higher than clinical used $\mathrm{Gd}$ complexes $\left(4.25 \mathrm{mM}^{-1} \mathrm{~s}^{-1}\right)$.

The theranostic performance of $\mathrm{CuPPy}-\mathrm{NH}_{2} \mathrm{NPs}$ is tested with cancerous cells in vitro. $\mathrm{KB}$ cells are chosen to evaluate the photothermal ablation efficiency of $\mathrm{CuPPy}-\mathrm{NH}_{2}$ NPs. Before incubating $\mathrm{CuPPy}-\mathrm{NH}_{2} \mathrm{NPs}$ with $\mathrm{KB}$ cells, the colloidal stability is first tested towards different physical environment including water, saline, PBS, cell culture with and without serum (Figure 5A). After storage for 7 days, no obvious aggregation is found in all of the solutions except for PBS. However, the aggregated CuPPy- $\mathrm{NH}_{2}$ NPs could be redispersed in PBS for more than $20 \mathrm{~h}$ after shaking (Figure S8), which would not hinder the following applications in vitro and in vivo. Besides, $\mathrm{CuPPy}-\mathrm{NH}_{2} \mathrm{NPs}$ also exhibit good structural stability under laser irradiation. As shown in Figure 5B, the CuPPy- $\mathrm{NH}_{2}$ NPs remain good NIR photothermal converting capability after five cycles of heating up to $80{ }^{\circ} \mathrm{C}$ and cooling down to room temperature. The absorption spectrum also confirms that no obvious change happens after irradiated with higher laser energy (Figure 5C).
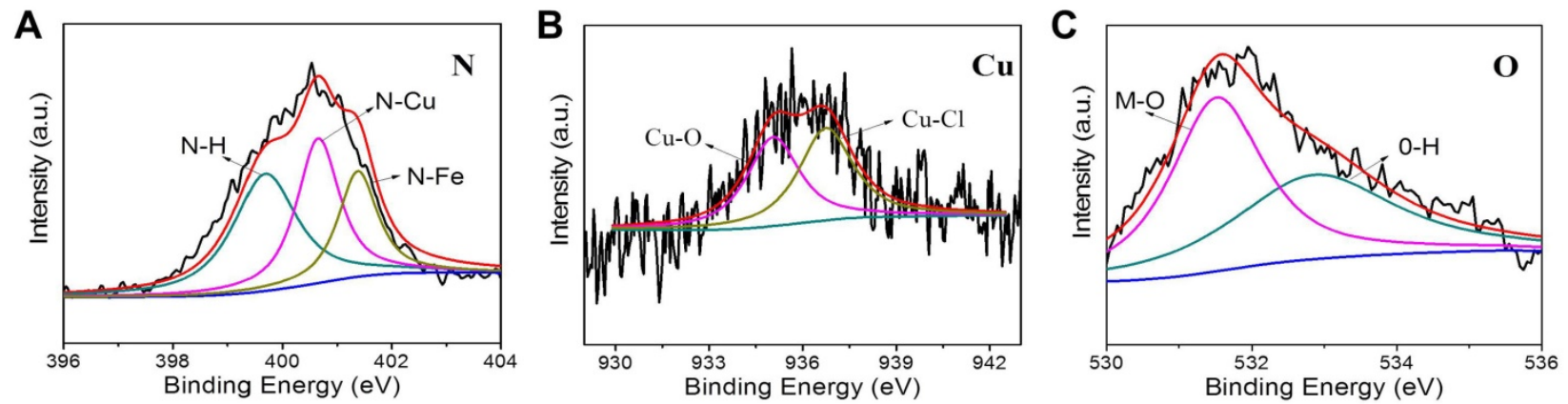

Figure 2. XPS N 1s (A), Cu 2p3/2 (B), and O 1s (C) spectra of the as-prepared CuPPy- $\mathrm{NH}_{2} \mathrm{NPs}$. 
Then, $\mathrm{CuPPy}-\mathrm{NH}_{2} \mathrm{NPs}$ and $\mathrm{PPy}^{-\mathrm{NH}_{2}} \mathrm{NPs}$ are incubated with $\mathrm{KB}$ cell at various concentrations for $24 \mathrm{~h}$ to evaluate the cytotoxicity. As revealed in Figure $6 \mathrm{~A}$, when the feeding concentration is below 100 $\mu \mathrm{g} / \mathrm{mL}, \mathrm{CuPPy}-\mathrm{NH}_{2}$ NPs could hardly cause any damages to the KB cells and the relative cell viability is high than $95 \%$. Further increasing the concentration to $200 \mu \mathrm{g} / \mathrm{mL}$, the cell viability remains $81 \%$. However, when the concentration reaches 400 $\mathrm{\mu g} / \mathrm{mL}$, only $58 \%$ of the KB cells survived after $24 \mathrm{~h}$, which may result from toxic component of $\mathrm{Cu}$ (II). The PPy-NH2 NPs have no obvious damage to KB cells, representing the low cytotoxicity. Hence, in the following photothermal ablation of $\mathrm{KB}$ cells, the

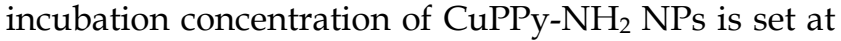
$50 \mu \mathrm{g} / \mathrm{mL}$ to avoid the toxicity caused cell damages. After irradiated by the $808 \mathrm{~nm}$ laser for $8 \mathrm{~min}$, the cell viability decreases with growing laser power densities. When the power density increases to 1.8 $\mathrm{W} / \mathrm{cm}^{2}$, nearly $50 \%$ of the $\mathrm{KB}$ cells are ablated to apoptosis (Figure 6B). Continuously increasing the laser power density to $3 \mathrm{~W} / \mathrm{cm}^{2}$, the majority of $\mathrm{KB}$ cells are dead and the cell viability decreases to $27 \%$. By comparison, the KB cells without incubation with $\mathrm{CuPPy}-\mathrm{NH}_{2} \mathrm{NPs}$ could hardly receive any damages after the same dosage of irradiation. Besides, the apoptotic cells after laser irradiation are further stained by FDA and PI (Figure 6C-F). FDA could only stain living cells with green fluorescence while PI could only stain apoptotic cells into red fluorescence. As exposed under laser irradiation for 0, 2, 4, $8 \mathrm{~min}$, the fluorescent images clearly exhibit that the green fluorescence is gradually replaced by red (Figure $6 \mathrm{C}-\mathrm{F}$ ), indicating the growing number of apoptotic cells. These evidences confirm that $\mathrm{CuPPy}-\mathrm{NH}_{2}$ NPs can effectively ablate $\mathrm{KB}$ cells under the $808 \mathrm{~nm}$ laser irradiation.

After in vitro tests, in vivo experiments are further performed to evaluate the potentials in tumor diagnosis and therapies. CuPPy$\mathrm{NH}_{2}$ NPs are i.v. injected into mouse bearing $\mathrm{KB}$ tumors. $24 \mathrm{~h}$ after injection, liver and renal functions are tested to reveal the short term safety of NPs. As shown in Figure S9, the injection of CuPPy-NH $\mathrm{N}_{2}$ NPs could hardly disturb the normal functions. Besides, MRI test is applied to trace the distribution of CuPPy- $\mathrm{NH}_{2} \mathrm{NPs}$ in tissues and organs (Figure 7). Comparing with blanket controls, the mice injected with NPs exhibit enhanced MRI signals in heart, lungs, kidneys, spleen and liver, as well as other tissues like muscles and lymphs. The NPs are mainly consumed by liver and kidneys, and the accumulation rate is 10.2 and 12.0 injected dose per gram tissue (\% ID/g) (Figure 7A). It should be noted that the accumulation of NPs in tumor area is also significant, which favor the diagnosis of tumor. The tumor size, shape and edges are clearly shown in $\mathrm{T}_{1}$-weighted MRI images (Figure 7F). As determined by ICP-AES, the $\mathrm{KB}$ tumor uptake rate is $5.7 \% \mathrm{ID} / \mathrm{g}$. In addition to tumor diagnosis
Figure 4. (A) Transverse relaxation time $\left(\mathrm{T}_{1}\right)$ relaxation rates $\left(\mathrm{r}_{1}\right)$ for $\mathrm{CuPPy}-\mathrm{NH}_{2} \mathrm{NPs}, \mathrm{Cu}(\mathrm{II})$ and $\mathrm{Fe}(\mathrm{III})$ (B) The concentration-dependent $\mathrm{T}_{1}$-weighted MRI under 1.5 T magnetic field for $\mathrm{CuPPy}_{\mathrm{N}} \mathrm{NH}_{2} \mathrm{NPs}, \mathrm{Cu}(\mathrm{II})$ and $\mathrm{Fe}(\mathrm{III})$. 
in MRI, the CuPPy-NH $\mathrm{N}_{2} \mathrm{NPs}$ remained in tumor tissue could also perform combination tumor therapies. $\mathrm{KB}$ tumor is a fast growing malignant tumor, and the tumors in control group can expand from 100 to more than $2200 \mathrm{~mm}^{3}$ within 16 days without any depressions (Figure 8A and C). When an $808 \mathrm{~nm}$ laser is applied to irradiate the tumors without NPs injection at the power density of $0.33 \mathrm{~W} / \mathrm{cm}^{2}$, the tumors could hardly observe any damages based on the observation of H\&E stained tumor slices, and the average tumor volume could reach more than 2000 $\mathrm{mm}^{3}$ (Figure 8A, D, S10). However, the tumors receive i.v. injection of CuPPy- $\mathrm{NH}_{2} \mathrm{NPs}$ exhibit an obvious depression in size, which is attributed from the release of chemotherapeutic $\mathrm{Cu}$ (II) (Figure 8A, E). In order to reveal the metal ion release mechanism, we incubate $\mathrm{CuPPy}-\mathrm{NH}_{2} \mathrm{NPs}$ in various environments containing different functional groups including the $-\mathrm{SH},-\mathrm{COOH}$ and $-\mathrm{NH}_{2}$ for $24 \mathrm{~h}$ (Figure S11A) [62, 63]. The results show that the released quantity of $\mathrm{Cu}$ (II) is the highest in $-\mathrm{SH}$, which may contribute from the strong coordination interactions with $-\mathrm{SH}$ [26]. In addition, the release of $\mathrm{Cu}$ from the NPs in serum is 3.5\% (Figure S12). This indicates that $\mathrm{Cu}$ is stable in serum. Since the microenvironment of tumor is acid and rich of $\mathrm{GSH}, \mathrm{Cu}$ (II) is more likely to release from the carriers after $\mathrm{CuPPy}-\mathrm{NH}_{2} \mathrm{NPs}$ reaching the tumor area, thus generating chemotherapeutic effects for KB tumors. As observed from the H\&E stained tumor
A

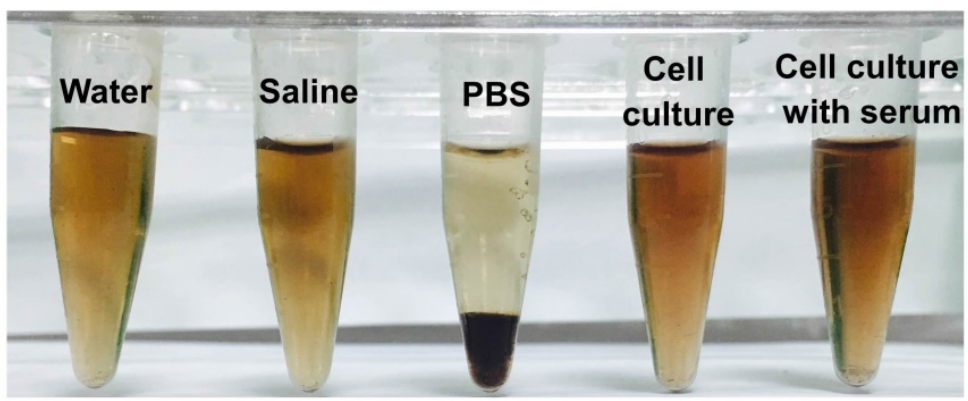

B

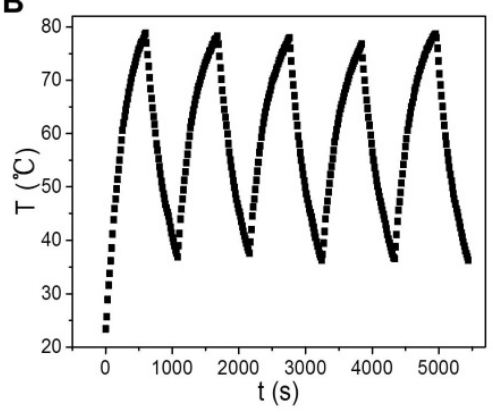

c

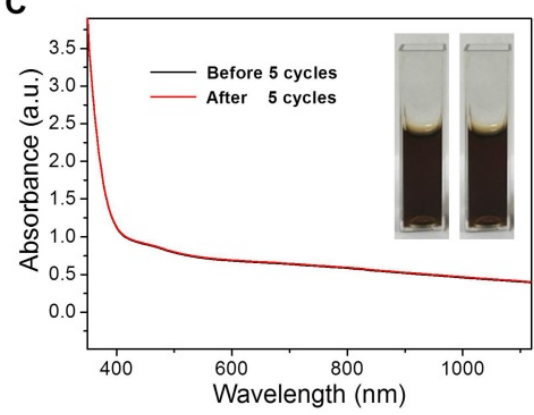

Figure 5. (A) Photographs of CuPPy-NH${ }_{2}$ NPs solution after incubation in pure water, saline, PBS, cell culture, and cell culture with $10 \%$ serum for 7 days. (B) The real-time temperature records of CuPPy- $\mathrm{NH}_{2}$ NPs solution as heating up and cooling down for 5 cycles at the time interval of $15 \mathrm{~s}$. The laser power density is $4 \mathrm{~W} / \mathrm{cm}^{2}$, and the concentration of CuPPy- $\mathrm{NH}_{2} \mathrm{NPs}$ is $1 \mathrm{mg} / \mathrm{mL}$. The absorption spectra of NPs solution before and after 5 cycles are compared in (C). slices, the locally damaged tumor tissue with broken cells and vanishing nuclear is the direct factor tumor depressions, and the tumor inhibition rate is $70.6 \%$ comparing with the control group. According to U.S. Food and Drug Administration, the maximum safe laser power density can be applied to animal bodies is $0.33 \mathrm{~W} / \mathrm{cm}^{2}$. Further combining the laser irradiation to perform thermochemotherapy (TCT), the tumors could be completely ablated under the power density of $0.33 \mathrm{~W} / \mathrm{cm}^{2}$ for $20 \mathrm{~min}$ (Figure $8 \mathrm{~A}, \mathrm{~F}$ ). Note that the concentration of $\mathrm{CuPPy}-\mathrm{NH}_{2} \mathrm{NPs}$ accumulated in the tumor sites is much higher than the injected concentration. So, the power density of $0.33 \mathrm{~W} / \mathrm{cm}^{2}$ is enough. The laser irradiation cause dramatic temperature increments in the local tumor area, and within in $16 \mathrm{~min}$, the central part reaches more than 55 ${ }^{\circ} \mathrm{C}$. In comparison, for the mice without i.v. injection of NPs, the temperature of tumor area only increases 5 ${ }^{\circ} \mathrm{C}$. Since the cancerous cells in tumor tissue could usually bear a mild environment below $43{ }^{\circ} \mathrm{C}$, large scales of damaged areas are observed from the H\&E stained tumor slices after TCT treatments. The destroyed tumor tissue is not recoverable and in the following 2 months, no tumor recurrence is observed from TCT groups. These evidences confirm that the CuPPy- $\mathrm{NH}_{2}$ NPs are of good tumor theranostic performance.

We also evaluated the biosafety of CuPPy- $\mathrm{NH}_{2}$ NPs. Since CuPPy-NH $\mathrm{N}_{2} \mathrm{NPs}$ are positive charged, it is capable to assist the tumor accumulation via EPR effect. The blood circulation half-life is $t_{1 / 2}=1.60 \pm 0.3 \mathrm{~h}$ by calculating (Figure 7B). This means that the $\mathrm{CuPPy}-\mathrm{NH}_{2} \mathrm{NPs}$ can be easily captured and removed by mononuclear macrophage system or reticuloendothelium, which avoids the accumulation in the body. After $24 \mathrm{~h}$, the biodistribution of the main organs and tumor are shown in Figure 7c. There is a high value in tumor area. Then, the MRI signal value and the relative MRI signal value of five vital organs and tumor also give the same conclusion revealed in Figure S13. There is a larger response signal in tumor because of the EPR effect. Meanwhile, as shown in Figure S13, there is a high value in the kidney and liver. It proves that NPs mainly exist in the kidney and liver through the circulation of the blood. Besides, the safety of CuPPy- $\mathrm{NH}_{2}$ NPs is further certified by H\&E stained. Compared with the control group, the internal organs include heart, liver, spleen, lung and kidneys cannot be fined 
any changes in the thermo-chemotherapy group (Figure S14). And the weights of the mice of the TCT group are stable (Figure $8 \mathrm{~B}$ ). All of these results indicate that the CuPPy- $\mathrm{NH}_{2} \mathrm{NPs}$ are potential safety agents in cancer diagnosis and treatment.
A
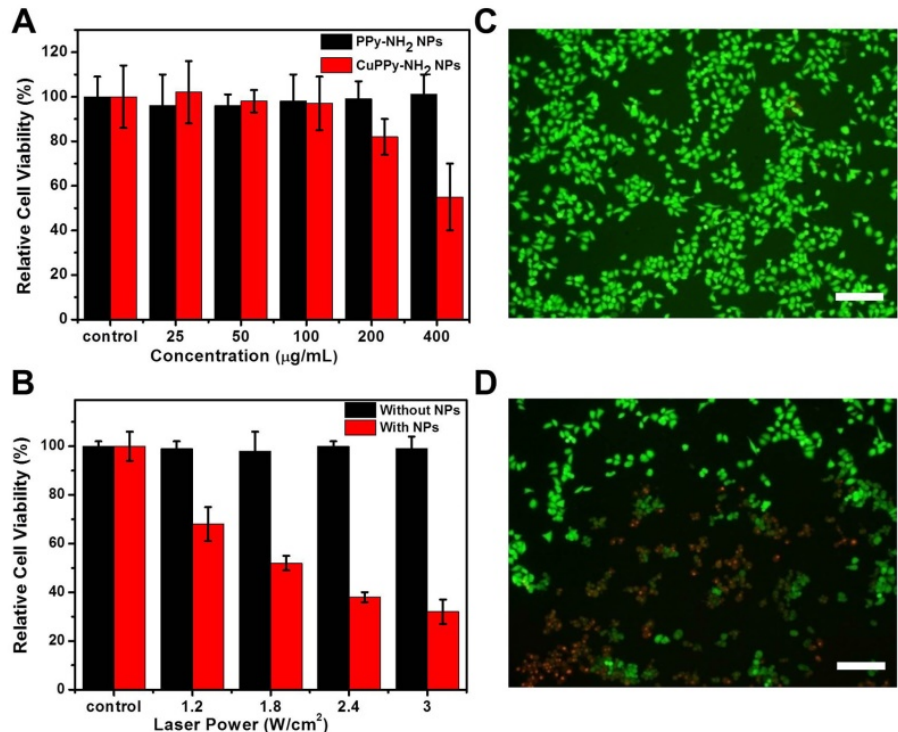

E

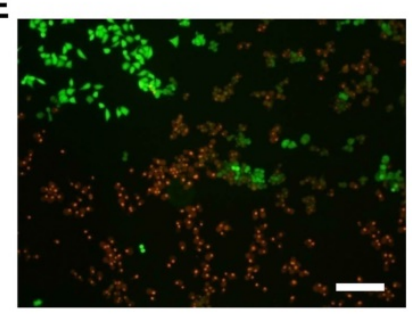

$\mathbf{F}$

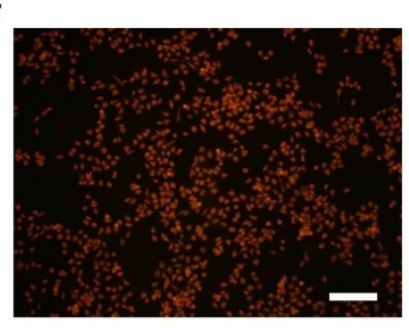

Figure 6. (A) The toxicity test of $\mathrm{KB}$ cells with CuPPy-NH $2 \mathrm{NPs}$ and PPy- $\mathrm{NH}_{2} \mathrm{NPs}$ in different concentration. (B) $\mathrm{KB}$ cells are incubated with or without $50 \mu \mathrm{mg} / \mathrm{mL}$ CuPPy- $\mathrm{NH}_{2} \mathrm{NPs}$ for $2 \mathrm{~h}$, and then they are irradiated by an $808 \mathrm{~nm}$ laser with the power density of $1.2,1.8,2.4$ and $3 \mathrm{~W} / \mathrm{cm}^{2}$ for $8 \mathrm{~min}$. Fluorescent images of PI and FDA co-staining cells after combined therapy for $0(\mathrm{C}), 3(\mathrm{D}), 8(\mathrm{E})$, and $10 \mathrm{~min}(\mathrm{~F})$, respectively. The scale bar in (C-F) represents $50 \mu \mathrm{m}$.
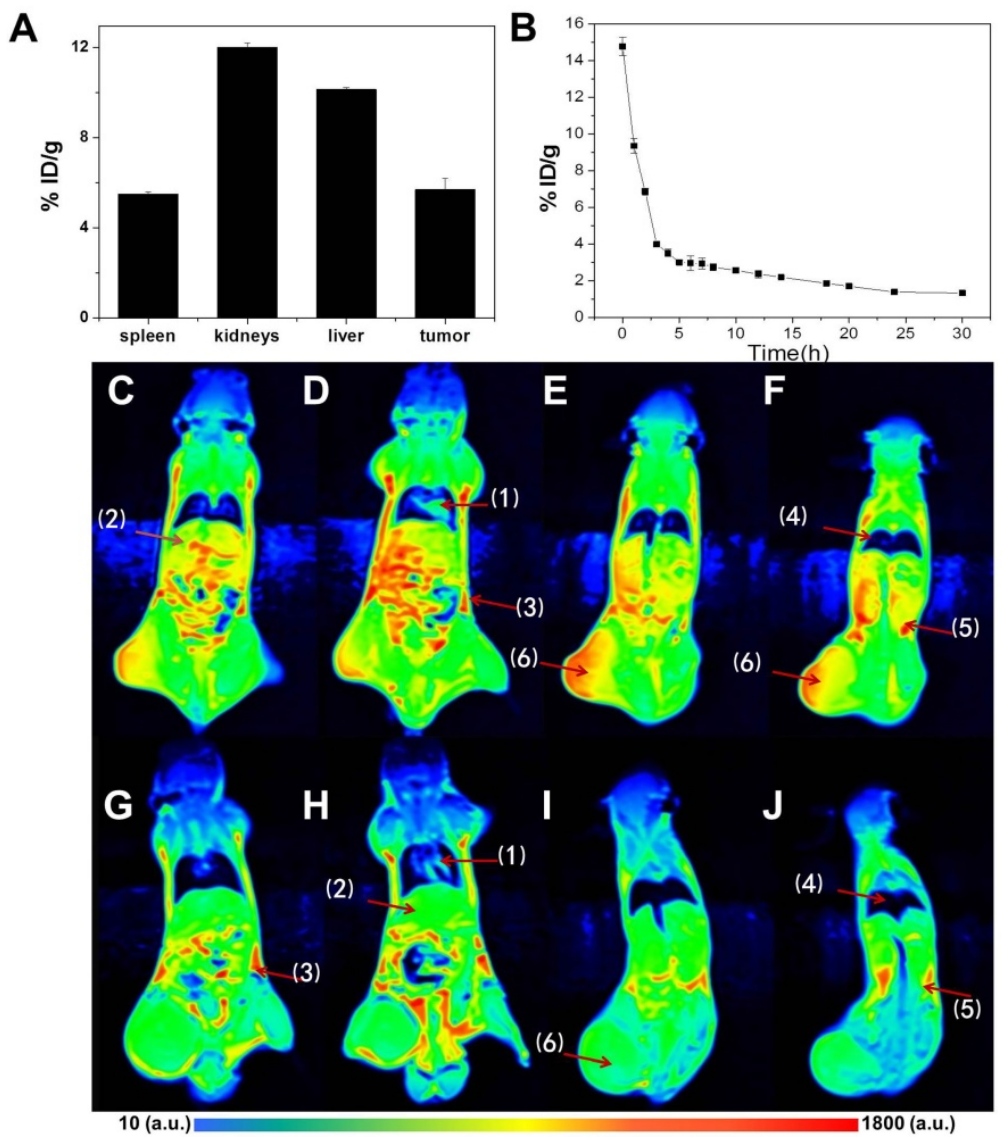

Figure 7. (A) Biodistribution of CuPPy- $\mathrm{NH}_{2} \mathrm{NPs}$ in KB-tumor-bearing mice at $24 \mathrm{~h}$ i.v. by determining the content of $\mathrm{Cu}$ (II) with ICP. (B) Blood circulation of CuPPy-NH $\mathrm{N}_{2}$ NPs in KB-tumor-bearing mice at $24 \mathrm{~h}$ i.v.. (Figure C-F) The MRI after the injection of NPs. (Figure G-J) The MRI before the injection of NPs. Organs identified by (1)-(6) represent heart, liver, spleen, lungs, kidneys and tumor, respectively. The inset color bar from blue to red represents the MRI signal from low to high. 

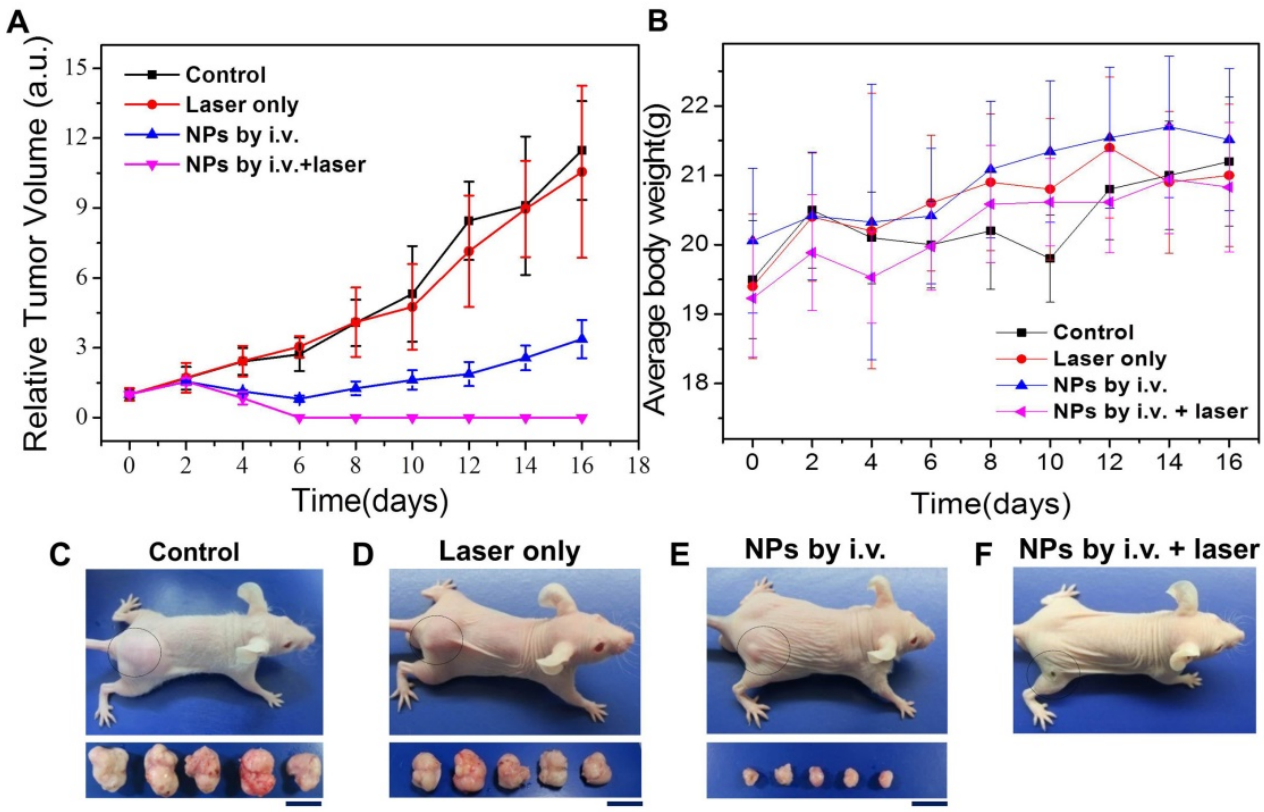

Figure 8. Photothermal therapy of KB tumors in vivo. (A) Relative tumor volume growing trend. (B) Average body weight for each group. (C-F) Photographs of typical mouse bearing tumor model and tumors taken from each group in the 16th day. The scale bar in (C-F) represents $20 \mathrm{~mm}$.

\section{Conclusions}

In summary, we demonstrate a convenient and efficient fabrication of CuPPy- $\mathrm{NH}_{2} \mathrm{NPs}$ with excellent tumor theranostic performance. The $\mathrm{CuPPy}-\mathrm{NH}_{2} \mathrm{NPs}$ are prepared through oxidation polymerization at room temperature and their function is enriched by the doping of transition metal ions. Due to the strong absorption in the NIR region, $\mathrm{CuPPy}-\mathrm{NH}_{2} \mathrm{NPs}$ have the function of photothermal therapy. The doped $\mathrm{Cu}$ ions also show the potential of chemotherapy. With unpaired electrons in atomic orbits, $\mathrm{Cu}$ ions is able to shorten the $\mathrm{T}_{1}$ of protons and light up the target area in $\mathrm{T}_{1}$-weighted imaging. Furthermore, $\mathrm{CuPPy}-\mathrm{NH}_{2}$ NPs have good light stability, photothermal stability, biosafety and low toxicity. This kind of transition metal-doped polymer gives a competitive approach for designing and fabricating multimodal theranostic nanoplatforms.

\section{Abbreviations}

PPy: Polypyrrole; NPs: nanoparticles; $\mathrm{PPy}_{\mathrm{NH}}$ : Polyaminopyrrole; MRI: magnetic resonance imaging; $\mathrm{CuPPy}-\mathrm{NH}_{2}: \mathrm{Cu}(\mathrm{II})$ and $\mathrm{Fe}(\mathrm{III})$ co-loaded polyaminopyrrole; CuPPy: $\mathrm{Cu}(\mathrm{II})$ and $\mathrm{Fe}(\mathrm{III})$ co-loaded polypyrrole; EPR: enhance permeability and retention; PI: propidium iodide; FDA: fluorescein diacetate; $\mathrm{FeCl}_{3} \cdot 6 \mathrm{H}_{2} \mathrm{O}$ : Ferric trichloridehexahydrate; $\mathrm{CuCl}_{2} \cdot 2 \mathrm{H}_{2} \mathrm{O}$ : copper chloride dihydrate; MTT: 3-(4,5dimethyl-2-thiazolyl)-2,5-diphenyl-2-H-tetrazoliumbr omide; MA: mercaptoethylamine; MPA: 3-mercaptopropionic acid; GSH: glutathione; $\mathrm{NH}_{3} \cdot \mathrm{H}_{2} \mathrm{O}$ :
Ammonium hydroxide; $-\mathrm{NH}_{2}$ : ammonia; -COOH: sodium citrate; -SH: mercaptoglycerol; ICP-AES: Inductively coupled plasma-atomic emission spectrometry; KB: human oral epithelial carcinoma; OD: optical density; i.v.: intravenous; L: the tumor sizes in long axes; D: the tumor sizes in short axes; H\&E: hematoxylin-eosin; UV-vis: UV-visible; TEM: transmission electron microscopy; DLS: dynamic light scattering; IR: infrared ray; XPS: X-ray photoelectron spectroscopy; $\eta$ : the photothermal transduction efficiency; $\mathrm{T}_{1}$ : longitudinal relaxation; $\mathrm{r}_{1}$ : respective relaxation rate; NMR: nuclear magnetic resonance; TCT: thermochemotherapy.

\section{Acknowledgments}

This work was supported by National Natural Science Foundation (51603084), JLU Science and Technology Innovative Research Team 2017TD-06, the Special Project from MOST of China, and the Fundamental Research Funds for the Central Universities. We also thank Animal Experiment Center, College of Life Science, Jilin University for the help in animal experiments.

\section{Supplementary Material}

Supplementary figures.

http://www.ntno.org/v02p0211s1.pdf

\section{Competing Interests}

The authors have declared that no competing interest exists. 


\section{References}

1. Wolfbeis O S. An overview of nanoparticles commonly used in fluorescent bioimaging. Chem. Soc. Rev. 2015; 44: 4743-4768.

2. Zhao Z, Fan H, Zhou G, et al. Activatable fluorescence/MRI Bimodal Platform for Tumor Cell Imaging via $\mathrm{MnO}_{2}$ Nanosheet-Aptamer Nanoprobe. J. Am. Chem. Soc. 2014; 136: 11220-3.

3. Tao W, Zhu X, Yu X, et al. Black Phosphorus Nanosheets as a Robust Delivery Platform for Cancer Theranostics. Adv. Mater. 2017; 29: 1603276-1603284.

4. Qin S Y, Zhang A Q, Cheng S X, et al. Drug self-delivery systems for cancer therapy. Biomaterials. 2017; 112: 234-247.

5. Gobbo O L, Sjaastad K, Radomski M W, et al. Magnetic Nanoparticles in Cancer Theranostics. Theranostics. 2015; 5: 1249-1263.

6. Tang Y, Yang T, Wang Q, et al. Albumin-coordinated assembly of clearable platinum nanodots for photo-induced cancer theranostics. Biomaterials. 2017; 154: $248-260$.

7. Goel S, England C G, Chen F, et al. Positron emission tomography and nanotechnology: A dynamic duo for cancer theranostics. Adv. Drug Deliver Rev. 2016; 113: 157-176.

8. Xuan Y, Yang M, Bo P, et al. Gold Nanomaterials at Work in Biomedicine. Chem. Rev. 2015; 115: 10410-10488.

9. Cheng X, Sun R, Yin L, et al. Light-Triggered Assembly of Gold Nanoparticles for Photothermal Therapy and Photoacoustic Imaging of Tumors In Vivo. Adv. Mater. 2017; 29: 1604894-1604900.

10. Liu Y, Yang M, Zhang J, et al. Human Induced Pluripotent Stem Cells for Tumor Targeted Delivery of Gold Nanorods and Enhanced Photothermal Therapy. ACS Nano. 2016; 10: 2375-2385.

11. Chen M, Tang S, Guo Z, et al. Core-shell Pd@Au Nanoplates as Theranostic Agents for In-Vivo Photoacoustic Imaging, CT Imaging, and Photothermal Therapy. Adv. Mater. 2014; 26: 8210-8216.

12. Cheng L, Wang C, Feng L, et al. Functional Nanomaterials for Phototherapies of Cancer. Chem. Rev. 2014; 114: 10869-939.

13. Zheng M, Liu S, Li J, et al. Integrating Oxaliplatin with Highly Luminescent Carbon Dots: An Unprecedented Theranostic Agent for Personalized Medicine. Adv. Mater. 2014; 26: 3554-3560.

14. Li L, Chen C, Liu H, et al. Multifunctional Carbon-Silica Nanocapsules with Gold Core for Synergistic Photothermal and Chemo-Cancer Therapy under the Guidance of Bimodal Imaging. Adv. Funct. Mater. 2016; 26: 4252-4261.

15. Bhattarai P, Dai Z. Cyanine based Nanoprobes for Cancer Theranostics. Adv. Healthcare Mater. 2017; 6: 1700262-1700285.

16. Liang $\mathrm{X}$, Fang $\mathrm{L}, \mathrm{Li} \mathrm{X}$, et al. Activatable near infrared dye conjugated hyaluronic acid based nanoparticles as a targeted theranostic agent for enhanced fluorescence/CT/photoacoustic imaging guided photothermal therapy. Biomaterials. 2017; 132: 72-84

17. Liu J, Chen $Q$, Zhu W, et al. Nanoscale-Coordination-Polymer-Shelled Manganese Dioxide Composite Nanoparticles: A Multistage Redox $/ \mathrm{pH} / \mathrm{H}_{2} \mathrm{O}_{2}$-Responsive Cancer Theranostic Nanoplatform. Adv. Funct. Mater. 2017; 27: 1605926-1605937.

18. Liu $\mathrm{Q}$, Song $\mathrm{L}, \mathrm{Chen} \mathrm{S}$, et al. A superparamagnetic polymersome with extremely high $\mathrm{T}_{2}$ relaxivity for MRI and cancer-targeted drug delivery. Biomaterials. 2016; 114: 23-33.

19. $\mathrm{Yu}$ J, Yin W, Zheng $\mathrm{X}$, et al. Smart $\mathrm{MoS}_{2} / \mathrm{Fe}_{3} \mathrm{O}_{4}$ Nanotheranostic for Magnetically Targeted Photothermal Therapy Guided by Magnetic Resonance/Photoacoustic Imaging. Theranostics. 2015; 5: 931-945.

20. Li J, Hu Y, Yang J, et al. Hyaluronic acid-modified $\mathrm{Fe}_{3} \mathrm{O}_{4} @ \mathrm{Au}$ core/shell nanostars for multimodal imaging and photothermal therapy of tumors. Biomaterials. 2015; 38: 10-21.

21. Li Z, Barnes J C, Bosoy A, et al. Mesoporous silica nanoparticles in biomedical applications. Chem. Soc. Rev. 2012; 41: 2590-605.

22. Zhang Z, Wang L, Wang J, et al. Mesoporous Silica-Coated Gold Nanorods as a Light-Mediated Multifunctional Theranostic Platform for Cancer Treatment. Adv. Mater. 2012; 24: 1418-1423.

23. Chen F, Hong H, Zhang Y, et al. In Vivo Tumor Targeting and Image-Guided Drug Delivery with Antibody-Conjugated, Radiolabeled Mesoporous Silica Nanoparticles. ACS Nano. 2013; 7: 9027-9039.

24. Fan W, Shen B, Bu W, et al. A smart upconversion-based mesoporous silica nanotheranostic system for synergetic chemo-/radio-/photodynamic therapy and simultaneous MR/UCL imaging. Biomaterials. 2014 * 35: 8992-9002.

25. Zhou M, Zhang R, Huang $\mathrm{M}$, et al. A Chelator-Free Multifunctional $\left[{ }^{64} \mathrm{Cu}\right] \mathrm{CuS}$ Nanoparticle Platform for Simultaneous Micro-PET/CT Imaging and Photothermal Ablation Therapy. J. Am. Chem. Soc. 2010; 132: 15351-8.

26. Wang Z, Huang $\mathrm{P}$, Jacobson $\mathrm{O}$, et al. Biomineralization-Inspired Synthesis of Copper Sulfide-Ferritin Nanocages as Cancer Theranostics. ACS Nano. 2016; 10: 3453-3460

27. Lv R, Yang P, Hu B, et al. In Situ Growth Strategy to Integrate Up-Conversion Nanoparticles with Ultra-Small CuS for Photothermal Theranostics. ACS Nano. 2017; 11: 1064-1072.

28. Ping $\mathrm{H}$, Oian $\mathrm{X}, \mathrm{Yu} \mathrm{C}$, et al. Metalloporphyrin-Encapsulated Biodegradable Nanosystems for Highly Efficient Magnetic Resonance Imaging-Guided Sonodynamic Cancer Therapy. J. Am. Chem. Soc. 2017; 139: 1275-1284.

29. Zhou J, Xiong Q, Ma J, et al. Polydopamine-Enabled Approach toward Tailored Plasmonic Nanogapped Nanoparticles: From Nanogap Engineering to Multifunctionality. ACS Nano. 2016; 10: 11066-11075.
30. Wang D, Zhou J, Chen R, et al. Core-Shell Metal-Organic Frameworks as $\mathrm{Fe}^{2+}$ Suppliers for $\mathrm{Fe}^{2+}$-Mediated Cancer Therapy under Multimodality Imaging. Chem. Mater. 2017; 29: 3477-3489.

31. Wang $\mathrm{Y}, \mathrm{Wu} \mathrm{B}$, Yang $\mathrm{C}$, et al. Synthesis and Characterization of Mn:ZnSe/ZnS/ZnMnS Sandwiched QDs for Multimodal Imaging and Theranostic Applications. Small. 2016; 12: 534-546.

32. Yang X, Hong H, Grailer J J, et al. cRGD-functionalized, DOX-conjugated, and ${ }^{64} \mathrm{Cu}$-labeled superparamagnetic iron oxide nanoparticles for targeted anticancer drug delivery and PET/MR imaging. Biomaterials. 2011; 32: 4151-4160.

33. Zeng J, Cheng M, Wang $\mathrm{Y}$, et al. pH-Responsive Fe(III)-Gallic Acid Nanoparticles for In Vivo Photoacoustic-Imaging-Guided Photothermal Therapy. Adv. Healthcare Mater. 2016; 5: 772-780.

34. Liu $X \mathrm{~L}, \mathrm{Ng} \mathrm{C} \mathrm{T}$, Chandrasekharan $\mathrm{P}$, et al. Synthesis of Ferromagnetic $\mathrm{Fe}_{0.6} \mathrm{Mn}_{0.4} \mathrm{O}$ Nanoflowers as a New Class of Magnetic Theranostic Platform for In Vivo $\mathrm{T}_{1}-\mathrm{T}_{2}$ Dual-Mode Magnetic Resonance Imaging and Magnetic Hyperthermia Therapy. Adv. Healthcare Mater. 2016; 5: 2092-2104.

35. Verwilst $P$, Park $S$, Yoon $B$, et al. Recent advances in Gd-chelate based bimodal optical/MRI contrast agents. Chem. Soc. Rev. 2015; 44: 1791-806.

36. Feng $\mathrm{C}, \mathrm{Bu} \mathrm{W}$, Zhang $\mathrm{S}$, et al. $\mathrm{Gd}^{3+}-$ Ion-Doped Upconversion Nanoprobes: Relaxivity Mechanism Probing and Sensitivity Optimization. Adv. Funct. Mater. 2013; 23: 298-307.

37. Siddiqui M M, Raisbahrami S, Turkbey B, et al. Comparison of MR/Ultrasound Fusion-Guided Biopsy With Ultrasound-Guided Biopsy for the Diagnosis of Prostate Cancer. Jama. 2015; 313: 390-397.

38. Dimopoulos M A., Hillengass J, Usmani S. Role of Magnetic Resonance Imaging in the Management of Patients With Multiple Myeloma: A Consensus Statement. J. Clin. Oncol. 2015; 33: 657-664.

39. Lin M, Wang $\mathrm{D}, \mathrm{Li} \mathrm{S}$, et al. Cu(II) doped polyaniline nanoshuttles for multimodal tumor diagnosis and therapy. Biomaterials. 2016; 104: 213-222.

40. Yang G, Gong H, Liu T, et al. Two-dimensional magnetic $\mathrm{WS}_{2} @ \mathrm{Fe}_{3} \mathrm{O}_{4}$ nanocomposite with mesoporous silica coating for drug delivery and imaging-guided therapy of cancer. Biomaterials. 2015; 60: 62-71.

41. Anthony L, Cacoub P, Macdougall I C, et al. Iron deficiency anaemia. Lancet. 2016; 387: 907-916.

42. Gubler C J, Lahey M E, Cartwright G E, et al. Studies on Copper Metabolism. IX. the Transportation of Copper in Blood. J. Clin. Invest. 1953. 199: 405-414.

43. Zhang F L, Song M R, Yuan G K, et al. A Molecular Combination of Zinc(II) Phthalocyanine and Tamoxifen Derivative for Dual Targeting Photodynamic Therapy and Hormone Therapy. J. Med. Chem. 2017; 60: 6693-6703.

44. Shahnaz R, Nazem G, Mardani M, et al. Co-Transplantation of Human Neurotrophic Factor Secreting Cells and Adipose-Derived Stem Cells in Rat Model of Multiple Sclerosis. Cell J. 2018; 1: 46-52.

45. Zhang P, He Z, Wang C, et al. In Situ Amplification of Intracellular MicroRNA with MNAzyme Nanodevices for Multiplexed Imaging, Logic Operation, and Controlled Drug Release. ACS Nano. 2015; 9: 789-798.

46. Nel A, Xia T, Mädler L, et al. Toxic potential of materials at the nanolevel. Science. 2006; 311: 622-627.

47. Zhao L, Peng J, Huang Q, Near-Infrared Photoregulated Drug Release in Living Tumor Tissue via Yolk-Shell Upconversion Nanocages. Adv. Funct. Mater. 2014; 24: 363-371.

48. Yang $\mathrm{K}, \mathrm{Xu} \mathrm{H}$, Cheng L, et al. In Vitro and In Vivo Near-infrared Photothermal Therapy of Cancer Using Polypyrrole Organic Nanoparticles. Adv. Mater. 2012; 24: 5586-92.

49. Chen M, Fang X, Tang S, et al. Polypyrrole nanoparticles for high-performance in vivo near-infrared photothermal cancer therapy. Chem. Commun. 2012; 48 : 8934-6.

50. Yang S, Li Z, Wang Y, et al. Multifunctional Bi@PPy-PEG Core-Shell Nanohybrids for Dual-Modal Imaging and Photothermal Therapy. ACS Appl. Mater. Interfaces. 2018; 10: 1605-1615.

51. Liu Y, Yang X, Huang Z, et al. Magneto-Plasmonic Janus Vesicles for Magnetic Field-Enhanced Photoacoustic and Magnetic Resonance Imaging of Tumors. Angew. Chem. Int. Ed. 2016; 55: 15297-15300.

52. $\mathrm{Li} \mathrm{Y}$, Tang J, $\mathrm{He} \mathrm{L}$, et al. Core-Shell Upconversion Nanoparticle@Metal-Organic Framework Nanoprobes for Luminescent/Magnetic Dual-Mode Targeted Imaging. Adv. Mater. 2015; 27: 4075-4080.

53. Chen Y, Ai K, Liu J, et al. Polydopamine-based coordination nanocomplex for $\mathrm{T}_{1} / \mathrm{T}_{2}$ dual mode magnetic resonance imaging-guided chemo-photothermal synergistic therapy. Biomaterials. 2015; 77: 198-206.

54. Yavuz MS, Cheng Y, Chen J, et al. Gold nanocages covered by smart polymers for controlled release with near-infrared light. Nat. Mater. 2009; 8: 935-939.

55. Huang X, Tang S, Liu B, et al. Enhancing the Photothermal Stability of Plasmonic Metal Nanoplates by a Core-Shell Architecture. Adv. Mater. 2011; 23: 3420-5.

56. Kim S E, Zhang L, Ma K, et al. Ultrasmall nanoparticles induce ferroptosis in nutrient-deprived cancer cells and suppress tumour growth. Nat Nanotechnol. 2016; 11: 977-985.

57. Shaffer T M, Harmsen S, Khwaja $E$, et al Stable Radiolabeling of Sulfur-Functionalized Silica Nanoparticles with Copper-64. Nano Letters. 2016: 16: 5601-5604.

58. Ellison P A, Feng C, Goel S, et al. Intrinsic and Stable Conjugation of Thiolated Mesoporous Silica Nanoparticles with Radioarsenic. ACS Appl. Mater. Interfaces. 2017. 9: 6772-6781 
59. Zhang Z, Xiong Z, Tao Z, et al. Structural study of compartmental complexes of europium and copper. J. Mol. Struct. 1999; 478: 23-27.

60. Dake L S, King D E, Czanderna A W. Ion scattering and X-ray photoelectron spectroscopy of copper overlayers vacuum deposited onto mercaptohexadecanoic acid self-assembled monolayers. Solid State Sci. 2000; 2: 781-789.

61. Willett R D, Jr C D, Kruh R F, et al. Crystal Structures of $\mathrm{KCuCl} 3$ and NH4CuCl3. J. Chem. Phys. 1963; 38: 2429-2436.

62. Bass L A, Mu W, And M J W, et al. In Vivo Transchelation of Copper-64 from TETA-Octreotide to Superoxide Dismutase in Rat Liver. Bioconjugate Chem. 2000. 11: 527-532.

63. Boswell C A, Sun X, Niu W, et al. Comparative in vivo stability of copper-64-labeled cross-bridged and conventional tetraazamacrocyclic complexes. J. Med. Chem. 2004. 47: 1465-1474. 